\title{
Structural Equation Modeling Applied to Socioeconomic Indicators in the Production of Sugarcane, in the State of Goiás
}

\author{
Jean Marc Nacife ${ }^{1}$, Frederico A. Loureiro Soares ${ }^{1}$, Marconi Batista Teixeira ${ }^{1}$, Leonardo Nazário S. dos Santos ${ }^{1}$ \& \\ Gustavo Castoldi ${ }^{1}$ \\ ${ }^{1}$ Department of Technical and Technological Education, Goiano Federal Institute (IF Goiano), Rio Verde, Brazil \\ Correspondence: Jean Marc Nacife, Department of Technical and Technological Education, Goiano Federal Institute, \\ Rio Verde, Brazil. Tel: 55-649-9963-4589.
}

Received: August 23, 2019

doi:10.5430/ijba.v10n5p53
Accepted: September 12, 2019 Online Published: September 17, 2019

URL: https://doi.org/10.5430/ijba.v10n5p53

\begin{abstract}
Agribusiness has played a strategic role for Brazil's development with the challenge of sustainable agriculture. It is proposed to determine, through Structural Equation Modeling (SEM), the validity and effects of the relationships between socioeconomic factors of the sugarcane production system in Quirinópolis, providing subsidies to the decision-making process of agricultural establishments. The research methodological approach was quantitative, applying techniques of normality statistics, hypothesis and multivariate analysis without statistical significance $(P$ $<0,05)$. A path diagram model was developed that presented structural quality adjustment and its validated explanatory equations, obtaining relevant $\mathrm{R}^{2}$. The results demonstrate that the Equation 1 (IBCcane $=0.02 \mathrm{Rcane}$ $0.75 \mathrm{ICcane}-0.46 \mathrm{ISVO}+0.35 \mathrm{ISPS}+$ error) is explained in $73.7 \%$ of its variance $\left(\mathrm{R}^{2}\right)$, in the Equation 2 (ICcane $=$ 0.59 ISVO -0.45 ISPS +0.35 SizeEstablis + error) successor vocation affects $42 \%$ on production costs and in the Equation 3 (Rcane $=-0.40$ AgroDistance - 0.16ISPS + error) the distance between farm and agribusiness influences $72 \%$ on the proposed revenue mix. The SEM analysis verified that social factors influence the economic factors that compose the sugarcane production system studied. The path diagram proved that the influence track relative to the costs in the proposed model is more representative than revenue for the economic results of rural sugarcane establishments.
\end{abstract}

Keywords: agricultural economy, benefit/cost index, path analysis, sugarcane agribusiness, rural development

\section{Introduction}

Agribusiness has become in Brazil a socioeconomic segment with a large impact on Gross Domestic Product (GDP), accounting for $34 \%$ of the workforce's employment and $22 \%$ of its value (IBGE, 2018a). The agricultural sector via major commodity producers and exporters has played a strategic role in the development of sustainable agriculture in the country, as it holds about $75.7 \%$ of arable land. Production systems as a business are challenged with the need to overcome the current simplified strategy for expanding new agricultural frontiers, which imposes social and environmental costs (Medina and Santos, 2017).

The expansion of sugarcane cultivation occupies a space of expression due to its structure, which involves sugarcane planting and industrialization to process sugar, biofuel and its derivatives in the cities, causing the perception of the emergence of mainly social and environmental problems, due to changes in land management and occupation (Trindade, 2015; Gilio and Moraes, 2016; Petrini et al., 2016; Petrini et al., 2017). The referred consequences of this new agricultural frontier are under debate because it mainly involves the fact of its competition with the agricultural production of food, framing as important negative impact of the exchange in the land use (Dauvergne and Neville, 2010; Maroun and Rovere, 2014).

Food security is a universal right in theory and requires access by all people at all times to the indispensable foods that address their nutritional needs for an active and healthy life (Pervaiz et al., 2017). Sugar-energy expansion has advanced in food crop areas often without a perspective of agri-food sustainability (Gilio and Moraes, 2016), creating doubts about the benefits caused by the process of land use change, as it expands yet in consolidated regions with high agricultural production (IBGE, 2018a).

Relevant braking in this procedure is due to the synergy of existing local infrastructure and logistics in the region, as 
previous studies have found that the economies of scale already available for traditional crops imply less vulnerability to sugarcane deployment (Trindade, 2015; Gilio and Moraes, 2016). In this context of enormous transformation in rural areas, agricultural innovations in production have been emerging, either for food or energy resources.

Sugarcane cultivation has gained great economic impetus in Brazil mainly since 2003 and has gained great importance with the continued expansion of the sector (Mendonça et al., 2013). Due to the current scope of the sugarcane production system, it is necessary to evaluate the effects of the transformation process of cultivated areas with crops and pastures (traditional activities), within the scope of social and economic sustainability.

The economic impacts are considerably positive with the introduction of sugarcane cultivation in order to meet the demands of agro-industries, but it is observed that this expansion is worrisome in Brazil, as it becomes monoculture and primordial economic base in the municipalities (Trindade, 2015; Gilio and Moraes, 2016). From the perspective of rural properties, succession is a socially important factor that, long before being effective, presents itself as an influential factor in the success of rural activity. They are impressive, especially in the formation of the operational cost of the rural establishment, the ability and vocation of the successor in relation to the rural activities. Burton and Fischer (2015) and Morais et al. (2017) assert that the ability of successors to accomplish agricultural activities and agribusiness management is paramount to the success of agricultural property.

The current world scenario has exogenous factors that impact through the process of globalization in the national agricultural economy, including the sugarcane market, imposing the technical preparation to measure the financial return of agricultural activity (Barnes et al., 2015), helping to confirm the understanding of the importance of planning as a feasible instrument for agribusiness. Agricultural production has adverse conditions to be faced whether agronomic, natural or market and the same applies to sugarcane crop, which is one of the most traditional in Brazil (Santos et al., 2016). Benefit/cost indicator analysis stabilizes as an important technique for determining the economic efficiency of global management actions (Špačková and Straub, 2015; FAO, 2016).

The measurement of agribusiness performance of each agent in an agroindustrial chain has become essential (Andia et al., 2011), however, from this perspective, the agricultural producer has no precise means of determining its profit margin due to the dynamics of the variables that compose its benefit/cost indicator. The current challenge of the rural establishment is more in the structure of formation of the benefit/cost indicator than in relation to the scale of production, due to the pricing imposed by the market (Andia et al., 2011).

Performance indicators have helped rural establishments to plan their management in a sustainable socioeconomic manner. In this regard, multivariate analysis is a formidable methodology for the elaboration and selection of impact factors in the results (Machado et al., 2015). The use of indicators to estimate sustainability has quite a grown in the last decades, including in the sugarcane production system, because it has as characteristic, the synthetic presentation of information and identification of the variables that best fit the proposed objectives (Guimarães et al., 2010).

The present study deals with statistical techniques, aiming to determine through the multivariate analysis of Structural Equation Modeling the validity and effects of the relationships between socioeconomic indicators referring to agricultural establishments that changed their agricultural production from sugarcane to sugarcane in the city of Quirinópolis, the main producer of the state of Goiás (IBGE, 2018a), providing subsidies to the decision making process of rural establishments to integrate or not to the sugarcane agroindustrial productive system.

\section{Method}

For the analysis of the process of influence among the socioeconomic factors of the agricultural establishments, it was necessary the statistical validation of variables and to establish their correlations. The field research had a quantitative approach and was conducted through semi-structured questionnaires that were applied to the owners of rural properties of the sugarcane production system from June 2018 to February 2019. The rural establishments studied are located in the rural microregions of the municipality of Quirinópolis, positioned geographically by the coordinates: $18^{\circ} 26^{\prime} 52^{\prime \prime}$ South and 50 $27^{\prime} 07^{\prime \prime}$ West, average altitude of 541 meters, located in the Southwest of Goiás and in the South mesoregion of Goiás (IBGE, 2018b).

\subsection{Sampling and Data Collection Procedures}

The research universe comprises the 67 agricultural establishments that make up the sugarcane production system (IBGE, 2018a), parameter for the sample calculation. The sample adopted the 95\% confidence level for data collection and analysis, with a sampling error margin of 5\%, resulting in a sample of 58 agricultural establishments (Santos, 2016). The research was of the quantitative type, with fieldwork adopting the survey method. In the data collection, printed questionnaires were used for the interviews. 
The data collection questionnaire was divided into two distinct sections, and in the first section general data were collected on the profiles of owners and agricultural establishments, and on the second the conceptions about the variables of research from the perspective of the social and economic dimensions. In the first phase of the research, a pre-test of the questionnaire was applied to check for inadequacies, inconsistencies and errors in the questions, which allowed to correct ambiguities and other identified nonconformities. The scope of application of the instrument covered 17 rural microregions in the municipality of Quirinópolis, State of Goiás - Brazilin, the collection of data (Figure 1).

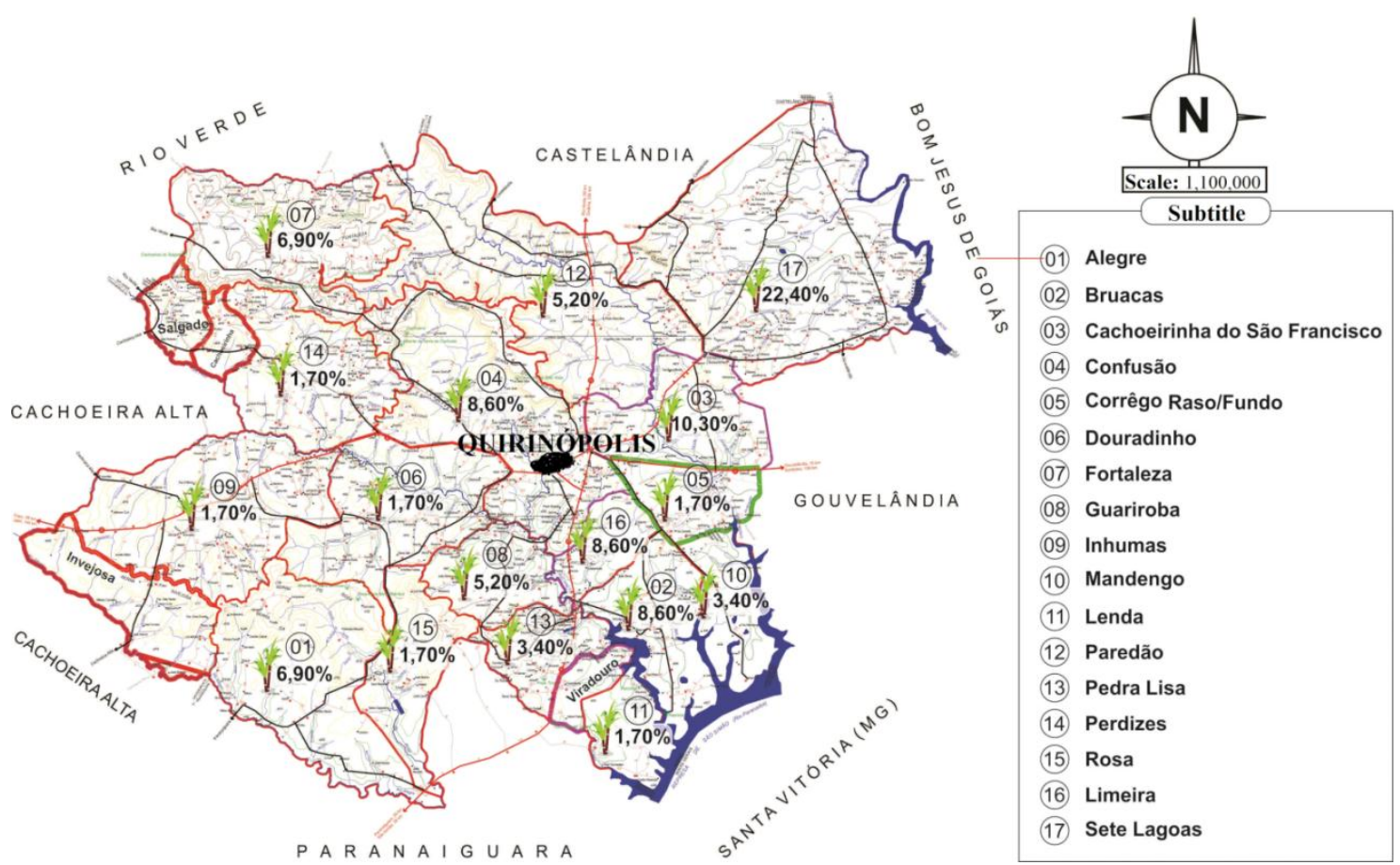

Figure 1. Map of the rural zone with the microregions of the city of Quirinópolis

Source: Adapted from Urzedo (2014)

The steps taken for the development of this study were:

(I) planning and preparation of questionnaires;

(II) evaluation of logistics application and data collection in agricultural establishments;

(III) data tabulation;

(IV) preliminary analysis of data, assessment of sample suitability and statistical measures;

(V) application of statistical tests of normality, standardization and control of multicollinearity (significance $\mathrm{P}$ $<0.05)$;

(VI) elaboration of the path diagram by the methodology Structural Equation Modeling; and

(VII) discussion on the relations between socioeconomic indicators.

\subsection{Indicators, Measures and Covariables}

Some statistical tests were performed for the validation of variables and the application of inference techniques. In this study, the relations of observable variables were analyzed: Index Benefit Cost by Cane (IBCcane), Index Costs by cane (ICcane), Remuneration by Cane (Rcane), Size of Establishment (SizeEstablis), Agroindustry Distance (AgroDistance), Index Succession Vocation (ISVO) and Index Succession Practical Skill (ISPS).

The elaboration of the structural equation modeling and path analysis were proposed in order to deepen the understanding of the socioeconomic indexes of agricultural establishments. For the articulation of the research proposal, it was also necessary to organize the indexes that measure the socioeconomic effects inherent to the characteristics of the agricultural establishments of Quirinópolis. To better understanding the proposed (variable) indicators, the following descriptions are presented: 
Succession Index - vocation (ISVO): it is measured by the arithmetic average obtained in the evaluation. The results of the scores in relation to the vocation of the successors in the management of the agricultural establishments attributed by the owners were observed in this study. The issues that shaped this indicator measured the vocation of successors to take over rural activities. The Likert scale of evaluation was used, which includes from 1 to 5 points and its equation is expressed:

$$
\overline{\mathbf{X}}=\frac{\sum_{\mathrm{i}=1}^{\mathrm{N}} \overline{\mathbf{X}_{\mathbf{i}}}}{\mathbf{N}}
$$

Succession index - practical skill (ISPS): it is measured by the arithmetic average obtained in the evaluation. The results of the scores were observed in relation to the ability of the successors to perform the technical and management activities of the agricultural establishments without considering the formal preparation. The Likert scale of evaluation was used, which comprises from 1 to 5 points and its equation is expressed:

$$
\overline{\mathbf{X}}=\frac{\sum_{\mathrm{i}=1}^{\mathrm{N}} \overline{\mathbf{X}_{\mathbf{i}}}}{\mathbf{N}}
$$

Benefit/Cost Index (IBCcane): it is the ratio of total compensation to total cost. The article applies the concept of cost index for sugarcane as a function of the total operational cost of sugarcane in (ICcane), calculated in relative percentage terms to the total income of the rural establishment. The $I C$ covers operational disbursements, such as supplies, labor, machinery, administrative expenses, labor costs and depreciation. For the purposes of this study, ICcane was calculated in relation to the 2017/2018 sugarcane harvest in the establishments. Your conversion calculation is shown by the expression:

$$
\mathbf{I C}_{\text {cane }}=\left[\frac{\text { Cost }}{\text { Remuneration }}\right]
$$

The remuneration comes from the production of sugarcane (Rcane) and was calculated based on the ton of sugarcane produced and converted by the quotation of Total Recoverable Sugar (ATR) by CONSECANA (2018), of July 10, 2018, and its currency conversion (real to U.S. dollar) was carried out on the same date based on the quotation of the Central Bank of Brazil. For the purposes of this study, the remunerations of agricultural establishments are prorated by the productive area in order to obtain the value of the compensation per hectare (US\$/ha) and to provide a calculation of the indicators.

In summary, the IBCcane is the simple ratio between the average of the remuneration (x) earned with the rural business by the percentage of the total operational costs $(\mathrm{y})$ required for production. The index uses a linear scale of assessment that includes negative and positive numbers (points). Its equation is determined by the expression:

$$
\overline{\mathbf{Z}}=\frac{\frac{\sum_{i=1}^{\mathrm{N}} \overline{\mathrm{x}_{\mathrm{i}}}}{\mathrm{n}}}{\frac{\sum_{\mathrm{i}=1}^{\mathrm{N}} \overline{\mathrm{y}_{\mathrm{i}}}}{\mathrm{n}}}
$$

Size Factor of the agricultural establishment (SizeEstablis): it is measured by the size of the rural property, an important variable for cost analysis and potential remuneration. In this study, establishments were identified in the small, medium, and large size classes, having as unit of measure the hectare (ha).

Distance factor between agricultural establishment and agribusiness (AgroDistance): it is measured by the distance from the rural property and agro-ethanol industry, this logistic factor impacts on the analysis of potential costs and remunerations. The average distance in this research uses the kilometer $(\mathrm{km})$ as unit of measure.

\subsection{Statistical Analysis}

Statistical analysis started with the evaluation of variables (SizeEstablis, AgroDistance, IBCcane, ICcane, Rcane, ISVO and ISPS), calculating the representative descriptive values of the sample and verifying the distribution of the data through asymmetry, with normality tests and hypotheses in the samples. For preparation and execution of the SEM analysis, preliminary statistical tests were applied to the database: I) The data were standardized and submitted to boxplot analysis to verify discrepancies, II) Normality tests (Kolmogorov-Smirnov and Shapiro-Wilk) of the data to support the assumption of normality of data distribution and III) Friedman's ANOVA test to verify that the null hypothesis $H_{0}$ was rejected. A test that uses the ranks of the data instead of their raw values for multiple comparisons (Hair. et al., 2010).

The analytical stage consisted in elaborating the path diagram and processing the SEM multivariate analysis, a 
methodology that combines exploratory factorial analysis and multiple regression (Sanchez et al., 2015). In the elaboration of SEM, the independent variables are considered exogenous and the dependent variables are similar to the endogenous variables. Both exogenous and endogenous variables can be observed or not, depending on the model being tested (Abadi, 2019).

For the exploitation of data, statistical testing and multivariate analysis, IBM@ SPSS Statistics, version 24.0 and Microsoft ${ }^{\circledR}$ Office Excel applications were used. The SEM analysis in this article used the IBM ${ }^{\circledR}$ SPSS Amos software, version 26.0 as a method of estimation and modeling. To interpret the results, it was considered the criteria adopted by Abadi (2019), Correia et al. (2012) and Sanchez et al. (2015). The proposed theoretical model related to the basic hypothesis of research analyzed presents hypothetically relevant influence relations, which were tested to verify their validity and effects.

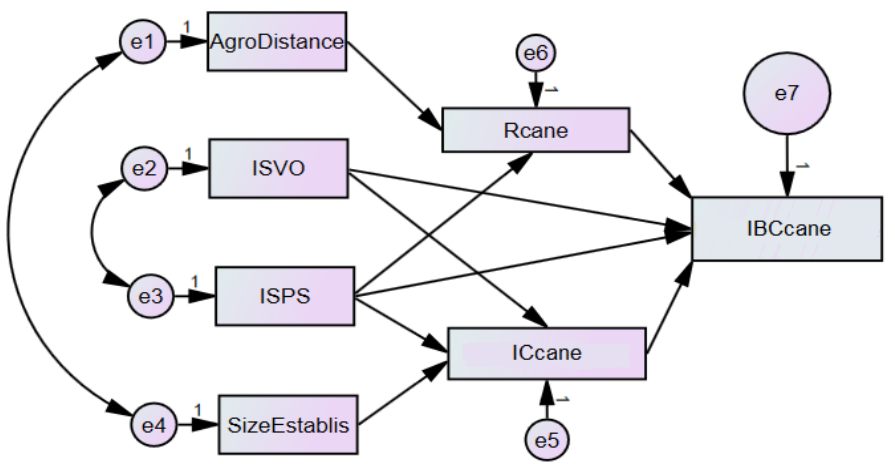

Figure 2. Theoretical model of the basic hypothesis proposed

Through SEM, the model can be tested using adequacy indicators to determine if the variance pattern in the data is consistent via the path diagram indicated by the authors (Correia et al., 2012). SEM was used to test the influence of variables and their effects on the prediction of the benefit/cost index for agricultural establishments in the productive center of Quirinópolis, Goiás. It is appropriate to approach SEM in two phases: the assessment of the adjustment of the measurement model and the structural evaluation of the model (Hair. et al., 2010).

The equations derived from the model were evaluated considering the following criteria: $\mathrm{R}^{2}$ values equal to or greater than 0.26 of substantial influence, $R^{2}$ between 0.13 to 0.25 of moderate influence and $R^{2}$ of less than 0.13 of weak influence (Cohen, 1988). The quality indicators of structural adjustment follow criteria established by several authors and are brought to reference the results of the SEM analysis (Table 1).

Table 1. Structural adjustment quality indexes for standard model

\begin{tabular}{lll}
\hline Structural Adjustment Quality Indices & Abbreviations & Standard \\
\hline Adjustment of chi-square $\left(\mathrm{X}^{2}\right)$ and degree of freedom $(\mathrm{df})$ & $\mathrm{X}^{2} / \mathrm{df}$ & 0 to $\leq 2^{*,{ }^{* *}}$ \\
\hline Root Mean square Residual & RMR & $<0,05^{*, * *}$ \\
\hline Residual Mean Square Error of Approach & RMSEA & $<0,05^{*, * *}$ \\
\hline P-value Close (Confirmatory Factor Analysis) & PCLOSE & $>0,05$ to $1,00^{*, * *}$ \\
\hline Goodness of Fit Index & GFI & $>0,95$ to $\leq 1,00^{*, * *}$ \\
\hline Adjusted Goodness of Fit Index & AGFI & $>0,95$ to $\leq 1,00^{*, * *}$ \\
\hline Hoelter's Critical N & 0,05 and 0.01 & $\geq 200^{* * *}$ \\
\hline Relative Fit Index & RFI - rho1 & Next to $1,00^{*, * *}$ \\
\hline Comparative of adjustment Fit Index & CFI & Next to $1,00^{*, * *}$ \\
\hline Incremental Fit Index & IFI - Delta2 & Next to $1,00^{*, * *}$ \\
\hline
\end{tabular}

Source: *Abadi (2019), ${ }^{* *}$ Correia et al. (2012) and ***Garson (2009). 


\section{Results}

The analysis of the relations between the socioeconomic indicators of the agricultural establishments of the sugarcane production system demonstrated relational statistical validity for most of the hypotheses and measured effects on the model tracks. The theoretical proposal of structural modeling of the equation of the variables studied presented significant relations at 95\% confidence (Figure 3).

The Variance Inflation Factor (VIF) multicolenicity test was applied to the variables, verifying the minimum scores of 1,350 and a maximum of 3,544, a result not compatible with collinearity distortions; preliminary tests did not identify outlines in the data. The normality tests applied verified the probability distribution associated to the data by proximity of the normal sampling distribution, considered a significance of $\mathrm{P}<0.05$ (Table 2), and the Friedman ANOVA test refuted the null hypothesis at the confidence level of $95 \%$ (Table 2).

Table 2. Statistical tests of adequacy of the sample database

\begin{tabular}{lllll}
\hline & Normality Tests & \multicolumn{2}{l}{ Collinearity test } & Average of Indicators* \\
\cline { 2 - 4 } & Kolmogorov-Smirnov & Shapiro-Wilk & VIF & US\$ 248.61/ha ${ }^{l}$ \\
\hline Rcane (annual) & 0.200 & 0.003 & 1.350 & $246 \%$ \\
\hline IBCcane & 0.000 & 0.000 & 1.410 & $41 \%$ \\
\hline ICcane & 0.003 & 0.000 & 3.480 & 3,38 points \\
\hline ISVO & 0.000 & 0.000 & 3.544 & 3,68 points \\
\hline ISPS & 0.000 & 0.000 & 2.986 & 756,63 ha \\
\hline SizeEstablis & 0.000 & 0.000 & 1.611 & $22.03 \mathrm{~km}$ \\
\hline AgroDistance & 0.004 & 0.000 & 1.857 & $\begin{array}{l}\text { Reject the null } \\
\text { hypothesis. }\end{array}$ \\
\hline $\begin{array}{l}\text { Analysis of Variance of Friedman Factors by Related Sample } \\
\text { Stations }\end{array}$ & & &
\end{tabular}

The proposed relations were analyzed and the system performed multiple regressions to consolidate the model, identifying the structural coefficients, covalences, factor loads for each variable and their connections according to the elaborated path diagram (Figure 3), controlling the standardized parameter estimates.

\subsection{Model Adjustment}

The structural equation modeling process adopted demonstrated a good fit of the model through adjustment indexes presented by their scores and references (Table 2). In the selection of information to construct the diagram, the Akaike Information Criterion (AIC) was used at 38,572, a small value reflecting a suitable selection for the adjustment of the data. On the basis of the scores of $X^{2}$ (2.572) and the df (10) the chi-square fit relation with the degree of freedom (0.257) was calculated, which remained in a value range considered reliable since the closer to 0 , the more this index shows that it is appropriate (Sanchez et al., 2015; Abadi, 2019).

The RMR test he had his score of 0.035 . Thus, considering that a perfect fit is indicated by $R M R=0$, the value obtained was excellent. The RMSEA adjustment criterion (ideal fit RMSEA =0), obtained a score of 0 , indicating a perfect fit. The Pclose in this modeling reached the value of 0.994 for the proposed path diagram, which indicates a suitable adjustment (Abadi, 2019).

To estimate the maximum structural likelihood of the model, the value of 0.987 was calculated for the GFI index. The AGFI, which considers the degrees of freedom available to test the model, had a score of 0.965 , and the RFI, which measures the discrepancy and degrees of freedom for the model under evaluation, obtained a value of 0.973 . The IFI obtained in this model was 1.039. In the CFI, the score was 1,000. All results of this block indicate a very good fit for the proposed model (Sanchez et al., 2015; Abadi, 2019).

The Hoelter criterion is one of the adequacy measures developed to test whether the sample size is suitable for the proposed path diagram. It indicates, from the obtained data, if the sample size of the specified model is sufficient or not (Garson, 2009). Hoelter's assessment can be made with different significances, and in this study Hoelter $(0,05)$ scored the score of 406 and Hoelter $(0,01)$ the value of 515 , setting as appropriate the sample collected (Garson, 
2009).

In essence, it is inferred that the model of the proposed path diagram through the evaluation of the measured measurement adjustment indices proved to be fully adequate to the quality criteria required by the multivariate analysis Structural Equation Modeling, allowing to proceed to analysis of the paths effectively.

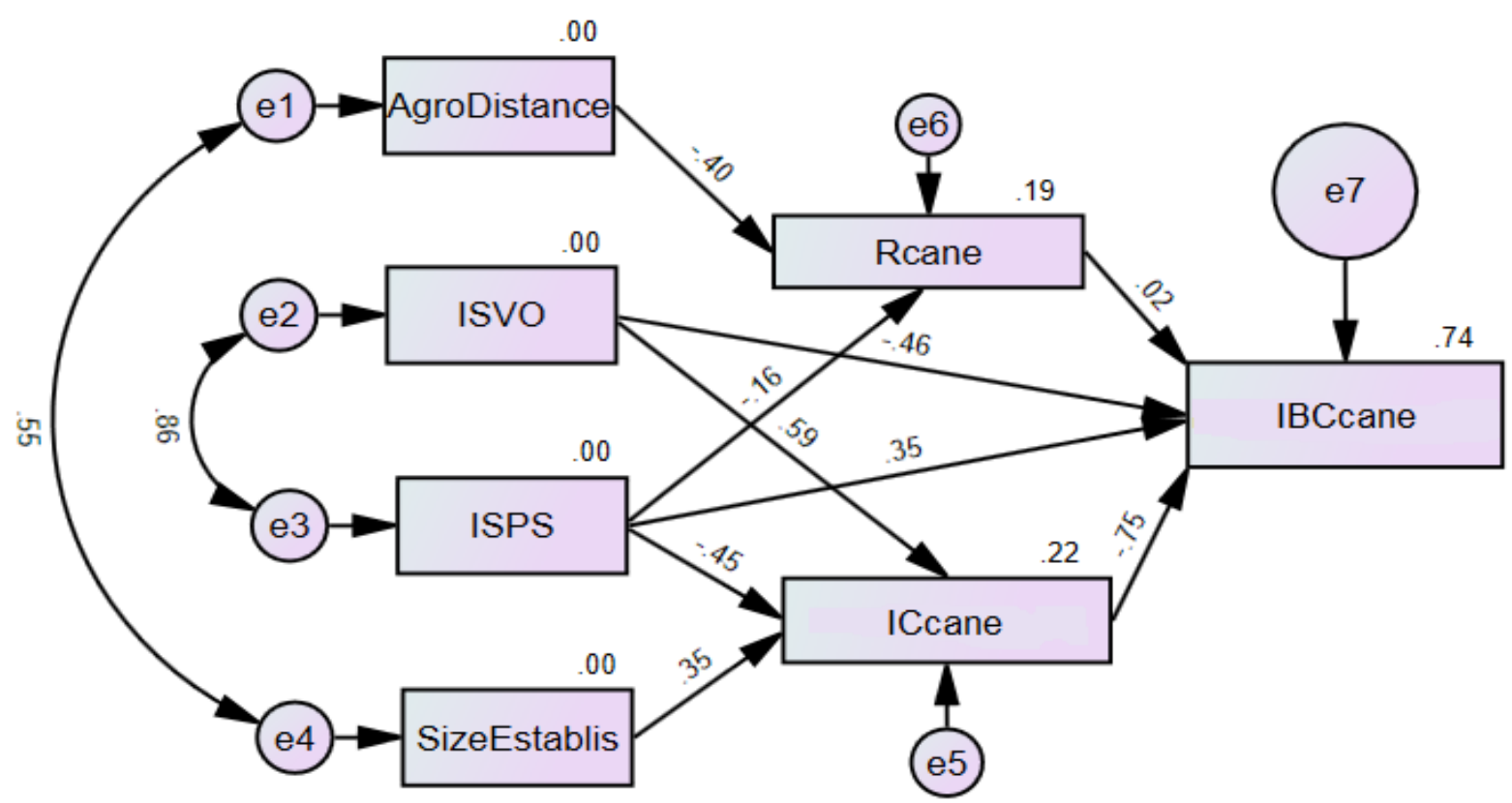

Figure 3. Path diagram relative to the proposed model for analysis: structural coefficients of relations and $\mathrm{R}^{2}$ of equations

\subsection{Evaluation of the Path Diagram Adjustment}

To validate the structural equation modeling, it was necessary to first check the quality of model adjustment, in which the tests are important to identify the compatibility of the main criteria of adjustment indexes obtained. The quality control indices of the model adjustment were satisfactory at the $95 \%$ confidence level $(\mathrm{P}<0.05)$, qualifying the model for the planned multivariate analyzes with the following values: $\mathrm{X}^{2} / \mathrm{df}=0.257$; RMR $=0.035$; RMSEA $=$ 0.000; Pclose $=0.994 ;$ GFI $=0.997 ;$ AGFI $=0.965 ;$ RFI-rho1 $=0.973 ;$ CFI $=1,000$, IFI - Delta2 $=1.039$; Hoelter $(0.05)=406$ and Hoelter $(0.01)=515$.

\subsection{Path Model}

In this section, the results of the study are reported based on standardized regression coefficients $(\beta s)$ and Ps for setting analysis parameters. From the estimated path diagram, the estimates and the parameters were calculated to verify if the hypotheses of simulated relation in the theoretical model are validated or denied, test conducted under a significance of 0.05 for the $95 \%$ confidence level.

For purpose of results and discursion of hypotheses (relation between variables) and consequently of the equations in detail, it was necessary to establish that, for a hypothesis to be accepted, two conditions must be satisfied: first, the value of the structural coefficient must be greater than 0.33 and second, $P$ should be less than 0.05 (Table 3 ). 
Table 3. The results of the path analysis for the standardized model with assessment of the structural coefficient, $\mathrm{P}$-value, equations and $\mathrm{R}^{2}$

\begin{tabular}{|c|c|c|c|c|c|c|c|c|}
\hline \multirow[t]{2}{*}{ Hypotheses } & \multicolumn{3}{|c|}{ Direct Effect Relations } & \multirow{2}{*}{$\begin{array}{l}\text { Structural } \\
\text { Coefficient }\end{array}$} & \multirow[t]{2}{*}{$p$-Value } & $\begin{array}{l}\text { Equation } \\
1 \\
\mathrm{R}^{2}\end{array}$ & $\begin{array}{l}\text { Equation } \\
2 \\
\mathrm{R}^{2}\end{array}$ & $\begin{array}{l}\text { Equation } \\
3 \\
\mathrm{R}^{2}\end{array}$ \\
\hline & & & & & & 0.737 & 0.215 & 0.188 \\
\hline H1 & Rcane & $<---$ & AgroDistance & -0.404 & $* * * *$ & & & $72 \%$ \\
\hline $\mathrm{H} 2$ & Rcane & $<--$ & ISPS & -0.156 & 0.190 & & & $28 \%$ \\
\hline H3 & ICcane & $<--$ & SizeEstablis & 0.347 & 0.003 & & $25 \%$ & \\
\hline $\mathrm{H} 4$ & ICcane & $<--$ & ISPS & -0.452 & 0.046 & & $33 \%$ & \\
\hline H5 & ICcane & $<--$ & ISVO & 0.587 & 0.010 & & $42 \%$ & \\
\hline H6 & IBCcane & $<--$ & Rcane & 0.023 & 0.736 & $1 \%$ & & \\
\hline $\mathrm{H7}$ & IBCcane & $\begin{array}{ll}<--- \\
\end{array}$ & ICcane & -0.752 & $* * * *$ & $47 \%$ & & \\
\hline $\mathrm{H} 8$ & IBCcane & $\begin{array}{l}<-- \\
\end{array}$ & ISPS & 0.355 & 0.009 & $22 \%$ & & \\
\hline H9 & IBCcane & $<---$ & ISVO & -0.457 & $* * * *$ & $29 \%$ & & \\
\hline
\end{tabular}

With the application of the path analysis technique, 7 direct relations were validated confirming the following hypotheses: hypothesis 1 proposes that the distance between the agricultural establishment with agribusiness is directly related to the remuneration earned by the activity with sugarcane in the agricultural establishment. The statistical significance for this hypothesis $(|0.000|<0.05)$ was verified, and, concomitant to the fact that its coefficient of structural effect was relevant $(\beta=|-0.404|>0.33)$, this hypothesis was accepted.

Hypothesis 3 refers to the size of the agricultural establishment is directly related to the composition of the agricultural establishment costs. The statistical significance for this hypothesis $(|0.003|<0.05)$ was verified, and, concomitant to the fact that its coefficient of structural effect was relevant $(\beta=|0.347|>0.33)$, this hypothesis was accepted.

Hypothesis 4 refers to the practical ability of the successor to conduct the activities of the rural establishment is directly related to the composition of the costs of the agricultural establishment. Statistical significance was found for this hypothesis $(|0.046|<0.05)$, and, concomitant to the fact that its coefficient of structural effect was relevant $(\beta$ $=|-0.452|>0.33)$, this hypothesis was accepted.

Hypothesis 5 was also accepted. In it, it is proposed that the vocation of the successor to conduct the activities of the rural establishment is directly related to the composition of the costs of the agricultural establishment. Statistical significance was found for this hypothesis $(|0.010|<0.05)$, and, concurrently, its coefficient of structural effect was relevant $(\beta=|-0.587|>0.33)$.

Hypothesis 7 refers that the impact of cost composition is directly related to the benefit/cost index of the agricultural establishment. Statistical significance was found for this hypothesis $(|0.000|<0.05)$, and, concomitant to the fact that its coefficient of structural effect was relevant $(\beta=|-0.752|>0.33)$, this hypothesis was accepted.

Hypothesis 8 proposes that the practical ability of the successor to conduct the activities of the rural establishment is directly related to the benefit/cost index of the agricultural establishment. Statistical significance was found for this hypothesis $(|0.009|<0.05)$, and, concomitant to the fact that its coefficient of structural effect was relevant $(\beta=$ $|0.355|>0.33)$, this hypothesis was accepted.

Hypothesis 9 refers that the vocation of the successor to conduct the activities of the rural establishment is directly related to the result of the benefit/cost index. Statistical significance was found for this hypothesis $(|0.000|<0.05)$, and, concomitant to the fact that its coefficient of structural effect was relevant, this hypothesis was accepted $(\beta=\mid$ $-0.457 \mid>0.33$ ).

Among hypotheses rejected, hypothesis 2 refers to the practical ability of the successor, which would be directly related to the remuneration obtained with the sugarcane. There was no statistical significance for this hypothesis $(|0.190|>0.05)$ and given the fact that its coefficient of structural effect was weak $(\beta=|-0.156|<0.33)$, this 
hypothesis was rejected.

Considering hypothesis 6 , which refers to the revenue obtained from sugarcane is directly related to the result of the benefit / cost index, there was no statistical significance for this hypothesis $(0.736>0.05)$, and, given the fact that its coefficient of structural effect was weak, this hypothesis was rejected $(\beta=|0.023|<0.33)$.

\subsection{Structural Analysis of the Paths}

The path diagram is composed of a set of equations that performs an integrated analysis of the structural model, in which they demonstrate relevant paths (Figure 3). The relation between the variables in the model is measured by the coefficients, and the closer to zero, the more it is considered unsatisfactory. The diagram proposed in this research is composed of three equations via observable variables, which were shown to be well adjusted structurally to the model.

The basic hypothesis was validated by checking the multiple square correlations of the endogenous variables that were estimated in the following measure: Equation 1 (IBCcane) is explained in $73.7 \%\left(\mathrm{R}^{2}\right)$ of its variance, emphasizing that it represents in the path diagram proposed the central hypothesis of this study, its scores are well adjusted structurally and its $\mathrm{R}^{2}$ is substantial. Equation 2 (ICcane) obtained an $\mathrm{R}^{2}$ equal to 0.215 , explaining its variance in $21.5 \%$, and Equation 3 (Rcane) with $\mathrm{R}^{2}$ equal to 0.188 , has been explained in $18,8 \%$ of their variance, being classified as moderate and accepted (Cohen, 1988).

Evaluating equation 1, it has that the articulation of the secondary hypotheses $6,7,8$ and 9 form a direct path, considering that hypothesis 6 was the only one rejected in the equation, which indicates that the revenue earned with sugarcane has no significant effect on the outcome of the benefit/cost ratio. The evaluations of the paths representing the revenues are important, since the expansion of the sugarcane production system has had economic effects, such as the increase in revenue in the cities where they were implemented (Gilio and Moraes, 2016; Nacife et al., 2019), but in the proposed diagram its irrelevance in the model can be explained from the observation of the variables and their relations (Figure 3) applied, inferring that this track had few integrated variables to better explain Rcane, which may have underestimated the representation of the effects on the IBCcane. Additionally, the formulation of revenue from the production or lease activity for the production of sugarcane is linked to market parameters of this commodity, which does not occur with the factors related to costs (CONSECANA, 2018).

Hypothesis 7 was accepted, indicating that cost management will affect the economic result expressed by the benefit / cost index of the agricultural establishment. In addition, the coefficient of effect for this hypothesis shows that each point of the IBCcane leads to -0.47 points of impact of the costs of the agricultural establishment, in other words, ICcane reduces the result of IBCcane by 0.75 per point. Cost management is an important factor in the productive process to determine the sustainability of the producer, who, in operations with commodities, has its price paid, so that cost is the primordial vector of success in the activity (Vilela et al., 2017).

Hypotheses 8 and 9 have been accepted and refer to the question of succession. The $\mathrm{H} 8$ indicates that the practical ability of the successor in the performance of the activities of the rural establishment will affect the economic result expressed by the benefit/cost index of the agricultural establishment. In this context, the successor with practical experience inserted in the management and production process of the agricultural establishment enhances the development and the future of it, since succession is fundamental to the future adaptability of the rural establishment in the agricultural sector (Wheeler et al., 2012).

Hypothesis 9 indicates that the vocation of the successor to carry out the activities of the rural establishment will affect the economic result expressed by the index of benefit/cost of the agricultural establishment. This finding about the vocation and practical ability of the successors, or potential successors shows that those involved with responsibility in the establishment of activities impact directly and / or indirectly in results (Inwood and Sharp, 2012).

Equation 2 is composed in its path of hypotheses that were all confirmed (Table 3). Hypothesis 3 has the pertinence of the direct effect between the size of the rural establishment and the cost index in cane production, presenting a positive relation, in which the result of the cost index of sugarcane activity is directly related to the size of the rural establishment, which can be explained by the fact that in the city the smallest rural properties are under contractual lease regime and the larger ones are predominantly under sugarcane supply regime for the agroindustry.

In a recent study, it was found that the rental system promotes a lower cost than providing production (Nacife et al., 2019), in order to explain the relation. The same occurs in other regions, where the cost of operations provides differentiation in the composition of the effective cost due to the size of rural establishments (Trindade, 2015; Gilio and Moraes, 2016). 
Hypotheses 4 and 5 refer to the effects on the performance of successors in rural establishments in the management of costs. It was verified that the causal relation between the practical ability of the successors and the cost index of the activity of sugarcane is inversely proportional. The relation between the vocation of the successor and the cost index of sugarcane activity is directly proportional. Thus, it is inferred that the ability to perform operational activities of production can reduce the cost and only the successor present vocation does not benefit the relation. Collaborating for this understanding are studies that point out that the great challenge to the success of current agriculture demands innumerable skills from successors, such as agricultural practices and management training (Burton and Fischer, 2015; Morais et al., 2017).

Equation 3 analyzes the path that aggregates the secondary hypotheses 1 and 2, in which hypothesis 1 was confirmed and hypothesis 2 rejected (Table 3). The hypothesis rejected in this equation indicates that the practical ability of the successors in this study does not affect significantly on the revenue earned as a function of sugarcane activity in rural settlements in Quirinópolis. The confirmed hypothesis presents a direct relation between the income of agricultural establishments and their distance from the agroindustry with a substantial inverse proportional effect between them, in other words, the greater the distance between the agroindustry and the agricultural establishment, the lower is the income earned by the establishment.

This finding is similar to other studies on this theme in relation to the sugarcane production system in Brazil that deal with economic viability, which point out that the sugarcane crop should be planted at a distance of approximately 50 $\mathrm{km}$ from an agroindustry in order to preserve the quality of the product and avoid losses (Gilio and Moraes, 2016; Spera et al., 2017). In relation to Quirinópolis, which was consolidated as the largest sugarcane pole in the state of Goiás (IBGE, 2018a), the greatest distance between agricultural establishments and agribusiness was $55 \mathrm{~km}$, but the general average distance was $22.03 \mathrm{~km}$, and the rural establishments classified as small-sized had a shorter distance $(15.11 \mathrm{~km})$ and medium and large ones showed an average distance of $24.11 \mathrm{~km}$ (Nacife et al., 2019).

From the path diagram, in this research it was observed that the path represented by the secondary hypotheses H5, $\mathrm{H} 7$ and $\mathrm{H} 9$ demonstrated the greatest direct and indirect effect (Figure 3). The variables of this track affect with a substantial effect load and with greater impact on the benefit/cost index of sugarcane production. On this track, the successors' vocation expresses a direct effect on the benefit / cost index with inversely proportional force (negative signal) and directly proportional (positive) force in its indirect path through the cost index to the IBCcane. Therefore, it can be inferred that the role of succession in rural establishments is important factor in the perspective and dynamism of the property, being able to configure the nature of the agricultural sector (Wheeler et al., 2012).

\section{Conclusion}

The social factors directly and indirectly influence the economic factors that make up the studied sugarcane production system. Structural Equation Modeling has proven to be valid and effective in discriminating relations between the most influential socioeconomic factors of the sugarcane production system. In addition, the path diagram has proved that the path relative to Equation 2 (costs) is more representative in the model than Equation 3 (revenues) in relation to the effects on the benefit/cost index of the agricultural establishments of the sugarcane. The study has limitations that can be resolved in new investigations, since the instrument and the research variables, despite meeting the statistical criteria, do not have variability of context, either geographic or temporal. It is clear that the theme must be researched from multiple aspects and contexts, but for the purposes of this research it was opted for the delimitation of the object, which allowed treating the theme with greater objectivity.

\section{Acknowledgements}

This research was supported by the Goiás Sugarcane Suppliers Association (APROCANA - Associação dos Fornecedores de Cana Goiás), Departments of Agriculture and Environment, Industry and Commerce and Tourism of the Quirinópolis City Hall, Faculdade Quirinópolis and led by the Graduate Program in Agricultural Sciences of the Goiano Federal Institute (IF GOIANO - Instituto Federal Goiano), Campus Rio Verde. We especially thank the institutional support of the Goiano Federal Institute (IF GOIANO), Campus Rio Verde. The opinions expressed in this article do not necessarily reflect the opinions of our supporters or partners.

\section{References}

Abadi, B. (2019). How agriculture contributes to reviving the endangered ecosystem of Lake Urmia? The case of agricultural systems in northwestern Iran. Journal of Environmental Management, 236, 54-67. https://doi.org/10.1016/j.jenv man.2019.01.111

Andia, L. H., Garcia, R., \& Bacha, C. J. C. (2011). The influence of economic and legal factors on the performance of Brazilian agribusiness companies: period from 2003 to 2005. Journal of Economics and Rural Sociology, 
49(4), 875-908. https://doi.org/10.1590/S0103-20032011000400004

Barnes, A. P., Hansson, H., Manevska-Tasevska, G., Shrestha, S. S., \& Thomson, S. G. (2015). The Influence of Diversification on long-term Viability of the Agricultural Sector. Land Use Policy, 1(49), 404-412. https://doi.org/10.1016/j.landusepol.2015.08.023

Burton, R. J. F., \& Fischer, H. (2015). European Society for Rural Sociology. Sociologia Ruralis, 55(2). https://doi.org.10.1111/soru.12080

Cohen, J. (1988). Statistical power analysis for the behavioral sciences (2nd ed.). Mahwah, New Jersey, USA: Lawrence Earlbaum Associates, Inc.

Consecana, Conselho de Produtores de Cana-de-Açúcar \& Açúcar e Etanol do Estado de São Paulo. (2018). Base de dados. Retrieved August 29, 2018, from https://www.consecana.com.br/login.asp?url=preco_mensal.asp

Correia, L., El-Ahmadi, A., Molle, B., Maia, R., \& Oliveira, I. (2012). Benchmark irrigation practices on olives using a Structural Equation Modelling approach. Irrigation and Drainage, 61, 189-200. https://doi.org.ez369.periodicos.Capes.gov.br/10.1002/ird.640

Dauvergne, P., \& Neville, K. J. (2010). Forests, food, and fuel in the tropics: The uneven social and ecological consequences of the emerging political economy of biofuels. The Journal of Peasant Studies, 37(4), 631-660. https://doi.org/10.1080/03066150.2010.512451

FAO - Food and Agriculture Organization of the United Nations. (2016). Economic Analysis of Animal Diseases. Retrieved August 2018, from http://www.fao.org/3/a-i5512e.pdf

Garson, G. D. (2009). Computerized Simulation in the Social Sciences: A Survey and Evaluation. Simulation \& Gaming, 40(2), 267-279. https://doi.org/10.1177/1046878108322225

Gilio, L., \& Moraes, M. A. F. D. (2016). Sugarcane industry's socioeconomic impact in São Paulo, Brazil: A spatial dynamic panel approach. Energy Economic, 58, 27-37. https://doi.org/10.1016/j.eneco.2016.06.005

Guimarães, L. T., Turetta, A. P. D., \& Coutinho, H. L. C. (2010). Approach to assessing the sustainability of sugarcane expansion in Mato Grosso do Sul - Brazil. Sociedade \& Natureza, 22(2), 313-327. https://doi.org/10.1590/S1982-45132010000200007

Hair, J. F. H. J., Black, W. C., Babin, B. J., \& Anderson, R. E. (2010). Multivariate Data Analysis (7th ed.). New Jersey, USA: Prentice Hall International, Inc.

IBGE - Instituto Brasileiro de Geografia e Estatística. (2018a). Censo Agropecuário: Resultados preliminares, 2017. Retrieved Januare 6, 2018, from https://sidra.ibge.gov.br/home/pms/brasil

IBGE - Instituto Brasileiro de Geografia e Estatística. (2018b). Cidades. Retrieved Januare 6, 2018, from http://cidades.ibge.gov.br/xtras/home.php

Inwood, S. M., \& Sharp, J. S. (2012). Farm persistence and adaptation at the rural-urban interface: Succession and farm adjustment. Journal of Rural Studies, 28(1), 107-117. https://doi.org/10.1016/j.jrurstud.2011.07.005

Machado, P. G., Picoli, M. C. A., Torres, L. J., Oliveira, J. G., \& Walter, A. (2015). The use of socioeconomic indicators to assess the impacts of sugarcane production in Brazil. Renewable and Sustainable Energy Reviews, 52, 1519-1526. https://doi.org/10.1016/j.rser.2015.07.127

Maroun, M. R., \& Rovere, E. L. (2014). Ethanol and food production by family smallholdings in rural Brazil: economic and socio-environmental analysis of micro distilleries in the State of Rio Grande do Sul. Biomass \& Bioenergy, 63, 140-155. https://doi.org/10.1016/j.biombioe.2014.02.023

Medina, G., \& Santos, A. P. (2017). Curbing enthusiasm for Brazilian agribusiness: The use of actor-specific assessments to transform sustainable development on the ground. Applied Geographym, 85, 101-112. https://doi.org/10.1016/j.apgeo g.2017.06.003

Mendonça, M. L., Pitta, F. T., \& Xavier, C. V. (2013). The Sugarcane Industry and the Global Economic Crisis. Amsterdam, The Netherlands: Transnational Institute and the Network for Social Justice and Human Rights (Report).

Morais, M., Binotto, E., \& Borges, J. A. R. (2017). Identifying beliefs underlying successors' intention to take over the farm. Land Use Policy, 68, 48-58. https://doi.org/10.1016/j.landusepol.2017.07.024

Nacife, J. M., Soares, F. A. L., \& Castoldi, G. (2019). Socioeconomic Characteristics and the Impacts of Land Use 
Changes to Sugar Cane in Quirinópolis, Brazil. Journal of Agricultural Science, 11(10), 180-193. https://doi.org/10.5539/jas.v11n10p180

Pereira Trindade, S. (2015). Agricultural aptitude, changes in land use, conflicts and direct and indirect impacts of sugarcane expansion in the southwestern state of Goiás. 2015. 187f. Thesis (Doctorate degree in Environmental Sciences), Universidade Federal de Goiás, Goiânia.

Pervaiz, B., Li, N., Manzoor, M. Q., \& Yaseen, M. (2017). Socio-Economic Characteristics of Farming Community and Food Security Situation in Punjab, Pakistan. Journal of Agricultural Science, 9(8), 130-142. https://doi.org/10.5539/jas.v9n8p130

Petrini, M. A., Rocha, J. V., \& Brown, J. C. (2017). Mismatches between mill-cultivated sugarcane and smallholding farming in Brazil: Environmental and socioeconomic impacts. Journal of Rural Studies, 50(2), 218-227. https://doi.org/10.1016/j.jrurstud.2017.01.009

Petrini, M. A., Rocha, J. V., Brown, J. C., \& Bispo, R. C. (2016). Using an analytic hierarchy process approach to prioritize public policies addressing family farming in Brazil. Land Use Policy, 51(2), 85-94. https://doi.org/10.1016/j.landusepol.2015.10.029

Sanchez, G. M., Nejadhashemi, A. P., Zhang, Z., Marquart-Pyatt, S., Habron, G., \& Shortridge, A. (2015). Linking watershed-scale stream health and socioeconomic indicators with spatial clustering and structural equation modeling. Environmental Modelling \& Software, 70, 113-127. https://doi.org/10.1016/j.envsoft.2015.04.012

Santos, D. F. L., Mendes, C. C., Farinelli, J. B. de M., \& Farinelli, R. (2016). Viabilidade econômica e financeira na produção de cana-de-açúcar em pequenas propriedades rurais. Custos e Agronegocio, 12(4), 222-254.

Santos, G. E. O. (2016). Cálculo amostral: calculadora online. Retrieved January 6, 2018, from http://www.calculoamostral.vai.la

Špačková, O., \& Straub, D. (2015). Cost-Benefit Analysis for Optimization of Risk Protection Under Budget Constraints. Risk Analysis, 35, 941-959. https://doi.org/10.1111/risa.12310

Spera, S., VanWey, L., \& Mustard, J. (2017). The drivers of sugarcane expansion in Goiás, Brazil. Land Use Policy, 66, 111-119. https://doi.org/10.1016/j.landusepol.2017.03.037

Strelecek, F., Zdenek, R., \& Lososová, J. (2011). Influence of the production change on the return to scale. Agricultural Economics, 57(4), 159-168. https://doi.org/10.17221/93/2010-AGRICECON

Urzedo, M. F. A. (2014). Quirinópolis: Cultura e Desenvolvimento Regional - Mãos e Olhares Diferentes III - 1832 2014. Goiânia: Kelps.

Vilela, S. D. J., Assis, L. P., Lopes, M. A., Silvestre, L. H. A., Santos, R. A., Resende, E. S., \& Martins, P. G. M. A. (2017). Economic and Productive Assessment of an Ordinary Small-Sized Dairy Enterprise in Southeast Brazil: A Multi-Year Study. Journal of Agricultural Science, 9(8), 143-154. https://doi.org/10.5539/jas.v9n8p143

Wheeler, S., Bjornlund, H., Zuo, A., \& Edwards, J. (2012). Handing down the farm? The increasing uncertainty of irrigated farm succession in Australia. Journal of Rural Studies, 28(3), 266-275. https://doi.org/10.1016/j.jrurstud.2012.04.001 